\title{
De las incertezas al tiempo subjetivo
}

\author{
Claudia López Neglia*
}

\section{Resumen / De las incertezas al tiempo subjetivo}

La búsqueda del lugar de la posición subjetiva, constituye el núcleo que interroga sobre la educación en el campo de la comunicación y el valor del lenguaje en la construcción del sujeto.

Cuestiones tales como la desaparición de certezas, el sustento del pensar el hacer o el hacer el pensar, el desmembramiento del arte, la ciencia, la ética y la aparición de una nueva herida narcisista, que hace presente la ausencia de emancipación e igualdad, organizan un anclaje en la visión dilemática de la realidad. Desde una óptica que destaca las barreras para las elecciones del sujeto, y exalta a la escritura como práctica constitutiva que puede permitirse burlar las reglas de la retórica, la autora reflexiona sobre los nuevos modelos culturales de juventud apoyados en el individualismo. Focaliza los modos que posibilitan establecer vínculos transferenciales para la construcción de un nuevo lazo, proponiendo al lenguaje, la nominación, la interpretación de signos, como oportunidad de producir una realidad, desde una dimensión simbólica, capaz de cohesionar y relacionar mejor el conjunto social.

\section{Descriptores}

Certezas / Escritura / Interioridad / Lenguaje / Mecanismo simbólico / Medios de comunicación / Significados culturales / Trascendencia

\section{Summary / From the uncertainties and the subjective time}

The searching of the subjective position place, constitutes the nucleus that questions on the education in the field of the communication and the value of the language in the subject construction.

Themes like the desertion of certainties, the support of thinking about the making and the making of the thinking, the dismemberment of the art, the science, the ethic and the apparition of a new narcissism wound that makes present the absence of emancipation and equality, organizes an stay in the dilemmatic vision of the reality.

From an optic that marks the barriers for the elections of the subject, and exalts to the writing as a constitutive practice that can evade the rules of the rhetoric, the author make a revelation about the new cultural models of youth based on the individualism. She focalizes the ways that make it possible to establish links of transference for the construction of a new connection, proposing to the language, the nomination, the interpretation of signs, as an opportunity for producing a reality, from a symbolic dimension, which is able to make a cohesion and to relate in a better way the social group.

\section{Resumo / Das incertezas ao tempo subjetivo}

A busca do lugar da posição subjetiva, constituem o núcleo que interroga acerca da educação no campo da comunicação e a importância da linguagem na construção do sujeito.

Questões como a desaparição das certezas, o sustento do pensar o fazer ou do fazer o pensar, desmembração da arte, a ciência, a ética, e a aparição da nova ferida narcisista que apresenta a ausência da emancipação e da igualdade, organizam uma ancoragem na visão dilemática da realidade. Desde uma óptica que salienta as barreiras para as eleições do sujeito, e exalta a escrita como pratica constitutiva que pode se permitir transgredir as regras da retorica, o autor reflete acerca dos novos modelos culturais de mocidade sustentados no individualismo.

Focaliza os modos que possibilitam estabelecer vínculos transferidores para a construção de um novo laço, propondo à linguagem, a nominação, a interpretação de signos, como oportunidade de produzir uma realidade, desde uma dimensão simbólica, que possa coesionar e relacionar melhor o grupo social.

Cuadernos del Centro de Estudios en Diseño y Comunicación. Ensayos. No 15 (2003). pp 51-58. ISSN 1668-0227

*Centro de Estudios en Diseño y Comunicación. infocedyc@palermo.edu

Claudia López Neglia: Licenciada en Psicología (UBA). Profesora de la Universidad de Palermo. 
¿Cómo hacer lugar a una posición subjetiva que viene decayendo, en una pérdida progresiva de la facultad simbólica bajo el predominio de lo imaginario especular; atadura a ver lo que los medios intentan mostrar como lo más real de lo real; alienación deshumanizante como correlato de un tiempo histórico, donde los discursos se quiebran, se fragmentan, pierden sentido, y las prácticas se ofrecen a lo inmediato, lo instantáneo,perdiendo la proyección hacia el futuro?

El quiebre de la cadena metafórica, como síntoma de un puro discurrir, no logra hacer marca ni anclarse, vía la implicación subjetiva. Este artículo propone la posibilidad de plantear un nuevo paradigma: "No busco, encuentro", para propiciar un tiempo subjetivo, enfrentado al tiempo de las certezas.

\section{Cultura y estado de sitio}

¿Cómo hacer pensar o pensar el hacer, cuando el gran muro donde habitaban las certezas fue derribado?

No es el lugar para "pensar" cómo, por qué, cuándo, y quiénes produjeron tal quiebre. Lo cierto es que el quiebre se instaló marcando por un lado una pérdida y por el otro una crónica obviedad anunciada en el discurso de diversas ciencias.

El arte, la ciencia y la ética que en la modernidad fueron concebidas bajo el ideal de una razón basada en principios lógicos, hoy, en el decir de Esther Díaz (1988), están desmembradas en la multiplicidad.

En un recorrido diacrónico, la historia ha ido construyendo su devenir atravesando distintas marcas, o heridas que tuvo, no sin dificultades, que elaborar.

Freud diría que el narcisismo del ser humano crea el obstáculo más sólido para el progreso de los conocimientos. La astronomía, la biología o el psicoanálisis sólo pudieron constituirse en ciencias después de haber vencido las creencias espontáneas, según las cuales la tierra es el centro del universo; el hombre, el rey del reino animal; el yo conciente, el centro de la personalidad. Creencias, imaginarios sociales, que son una proyección del antropocentrismo natural para el sujeto.

Una nueva herida narcisista se hace presente al comprobar que "la historia no dispone para nosotros ni la emancipación, ni la igualdad, ni la sabiduría. No nos une la promesa de un mañana mejor". (Díaz, Esther, 1988: 33).
Producto de esta nueva herida narcisista, fueron las ideologías que tomaron como mercancía el Fin de las Utopías, para especular con la libertad en ascenso de la subjetividad.

Por qué a la libertad en ascenso se la puede pensar como una mercancía con la cual especular a la hora de un nuevo hacer o un nuevo construir.

Si a una tesis modernista como Prohibido Prohibir, se le pudo oponer una antítesis posmoderna como Fin de las Utopías, a este binomio le falta producir una síntesis que permita relanzar el movimiento dialéctico a nuevas construcciones. Sin embargo todo parecería señalar un estancamiento en lo dilemático, donde no hay posibilidad de elección. Si no hay posibilidad de elección es porque todo lo que daba garantías ya no existe, garantías de verdades, saberes, producciones.

La falacia, o ingenuidad, sería creer que en algún momento de la corriente histórica, o de la historia personal sí hubo garantías, encontrándose el sujeto actual en la encrucijada de ¿para qué pensar o, para qué hacer?

\section{Juventud y transición}

Del sujeto actual que se hace imprescindible hoy hablar es del joven, que se encuentra ante un presente cultural desesperanzado, donde los discursos que lo atraviesan, se presentan ambiguos, vacíos de contenido, pero a la vez efectivistas a la hora de ofrecer la posibilidad de entrar en contacto con toda la información (vía correo electrónico, cable, Internet) que el mercado actual les pone en sus manos.

La influencia que han tenido los medios masivos de comunicación en las últimas décadas, penetrando y fortaleciendo su presencia dentro de la sociedad a través de un trastocamiento de las modalidades de comunicación social, llegaron a ocupar lo que en otros tiempos se situaban los vínculos interpersonales.

Desde los medios se impulsa al consumo, y se encuentra en los jóvenes el centro de atención por donde entrar, con mensajes repletos de códigos imperativos que comunican lo nuevo como única modalidad de la imagen; perdiendo la tradición, la ética, la moral y hasta la ley, su capacidad rectora y evidenciando su trivialidad, su banalidad.

El vacío resultante lo llena el mercado, fortaleciendo el narcisismo y el culto al cuerpo para pertenecer al reino de los pares, donde la salud y la enferme-dad se entraman en confusa convivencia. 
Lenguaje e imagen joven, son slogans que provocan en los posibles consumidores un efecto de individualidad, en un sentirse único, aunque no exterior al grupo de pares.

Pero a pesar de la devoción por el consumo, las escasas perspectivas de inserción y progreso se hacen también presentes para los que aspiren a trabajar e incorporarse en la actividad económica. Ilusión de libertad para elegir dentro de un contexto de individualismo social y de escasas posibilidades de proyectar.

Envuelto en cantidades de mensajes que lo ensordecen, el joven se encuentra inmerso en un bombardeo informatizado, que lo lleva a desplazar las reflexiones que provenían de la educación y de los distintos discursos las ciencias, como las armas para el desarrollo del conocimiento y su autonomía personal. Faltan las razones que peleen por las utopías, y el presente solo implica gratificarse, disfrutar ya, revalorizando la autonomía del egoísmo. Claro que dentro de esta apretada introducción, están también lo jóvenes que sufren las exclusiones y el aislamiento que promueven las políticas económicas vigentes, limitando la posibilidad de ingreso al mercado laboral, al desarrollo profesional, la formación de la familia, el acceso al consumo cultural, y que hoy piensan en emigrar, o emigran.

Quedan al margen de la oferta cultural, ubicándose en periféricos circuitos de consumo; las leyes del mercado promueven la oferta cultural a quienes puedan pagarla. La cultura hoy industrializada termina aplicando los mismos valores que la economía.

Dentro de este marco contextual, tanto social como político, económico, ideológico y cultural, la amenaza real de una pérdida de lugar en el mundo, afecta tanto los proyectos de jóvenes como adultos.

Pero el alcance de este escrito se dirigirá a la reflexión sobre un presente cultural desesperanzado, donde los jóvenes, nuestros estudiantes, aparecen como los más perjudicados del sistema, teniendo en cuenta que el tiempo de elaboración psíquica de la reedición edípica, el desprendimiento del núcleo de origen y la proyección de los ideales, se ven amenazados por ciertas propuestas culturales que en sus discursos paradojales idealizan al adolescente en su juventud pero lo ignoran en los requerimientos propios de su momento vital. Una cultura que promueve evitar el contacto con la propia interioridad, devalúa la dimensión proyectual, y estimula el repliegue narcisista de la satisfacción inmediata, señala significativamente la indeterminación de un lugar a ser construído para el futuro social. Unas breves líneas que caracterizan el período de transición del adolescente (como podemos observar en una gran mayoría de nuestros alumnos universitarios), serían oportunas para delinear el marco de referencia con el que trabajamos cotidianamente.

"...La mutación adolescente, signada de este modo por pérdidas que son la condición propiciatoria para la circulación deseante, se liga desde lo metapsicológico a la castración simbólica. La prohibición del incesto y la imposibilidad de realización plena del goce pulsional, se sientan en una lógica de la triangulación y de la incompletud que habrá de trazar los senderos de un deseo por siempre insatisfecho.

Desde el punto de vista identificatorio, este atravesamiento habilita al adolescente para la salida exogámica, y más ampliamente, para la búsqueda de su lugar en el mundo. Piera Aulagnier se ha referido extensamente a la importancia del proyecto identificatorio (aquello que el Yo espera devenir) relacionándolo con la posibilidad de asunción de la prueba de castración. La renuncia a los atributos de la certeza instala una diferencia entre el Yo actual y el Yo del tiempo futuro.

Así el yo renuncia a convertir el futuro en el lugar en el que el pasado podría retornar, para investir ideales futuros y un proyecto identificatorio tan singular como aún incierto en su posibilidad de realización." (Rojas, María C. y Sternbach, S., 1994:120)

Entonces el yo es tanto sede de renuncia como de espectativa, renuncia que implica duelo; y espectativa que anuncia una espera, intervalo y esperanza futura. Ambos son imprescindibles para el tránsito hacia el cambio, la madurez; sin duelo no se asume la pérdida, y sin esperanza no hay ideales futuros.

Este es el movimiento dialéctico entre el Yo ideal y el Ideal del Yo, que posibilita en el sujeto transitar su mundo incestuoso y narcisita, operando la castración simbólica, y habilitándolo para proyectar su futuro en tanto sujeto deseante. Hoy la exaltación de la juventud no conlleva su vertiente liberadora, que requiere del cuestionamiento de rígidos mandatos de épocas anteriores, sino que se exalta ante el terror de una adultez que se presenta como carente de productividad y bienestar, entonces de qué vale proyectar hacia el futuro.

Una frase de Santiago Kovadloff nos va a dar la llave desde la cual abrir la temática que ste texto propone: "Idealizar a los jóvenes es, en realidad, condenarlos al silencio. Acariciándoles 
el lomo con la mano tersa de la adulación, se les impide tomar la palabra. Decir qué les ocurre y cómo se ven desde su propio punto de vista". (Rojas, M.C. y Sternbach, S., 1994: 122)

Si nos detenemos a observar los discursos vigentes del poder, en sus vertientes políticas, sociales, económicas e idelógicas de nuestra época, donde reina a todas luces el triunfo de la corrupción, esto no es sin consecuencias; por el contrario implica un gran trastorno de la legalidad simbólica repercutiendo directamente en la relación narcisista del sujeto con la cultura. Si la ley bajo su forma simbólica requiere de enunciados que garanticen la no arbitrariedad para poder ser tramitados desde las distintas subjetividades, hoy esta función se encuentra destituída en sus representantes, perdiendo la sujeción a la ley y quebrando el orden simbólico. La regla en cambio será el ejercicio del poder a partir de los propios intereses.

El discurso de los medios de difusión no puede ser otro, aportando su cuota de banalización ante el horror violento de lo cotidiano, produciendo una creciente insensibilidad y falta de capacidad de reacción ante un presente naturalmente obsceno, donde lo real anestesiado es parte del espectáculo de la posmodernidad.

Los nuevos modelos culturales de juventud, apoyados en el individualismo antes señalado, bello, superficial, exitoso y divertido, promueven desestimar la interioridad, con las consecuencias que hoy vemos: problemas en el pensamiento, la simbolización y las modalidades operatorias. Prima el mandato de una precoz autonomía, dosis de hedonismo e individualismo que liberaría al joven posmoderno de las pesadas culpas del sujeto de la modernidad.

Ante la apariencia de un movimiento deseante, es el goce el que se escucha imperativamente. En su vertiente cruel, el Superyo, obsceno y feroz, ordena un goce como sometimiento a ese Otro absoluto e invasor, representado por la cultura y sus nuevos mandatos, pero disfrazado de formas de placer y libre elección. Queda abolido el deseo, irrumpiendo la escena un goce pulsional, que aparenta disfrazar el terror al futuro.

No es este el espacio para profundizar las transformaciones de la familia actual, las patologías parentales o violencia familiar, la pareja hoy, los modos de relacionarse entre sexos, ni tampoco para quedarse en un diagnóstico fundado en la evaluación de la sintomatología actual de los jóvenes, ligadas al narcisismo y sus articulaciones patológicas como las adicciones y las enfermedades psicosomáticas.

\section{En busca del tiempo subjetivo}

El punto central es poder preguntarnos ¿cómo establecer un vínculo transferencial con ellos, donde poder construir juntos, un nuevo lazo que les permita transitar la adolescencia para tramitar la constitución subjetiva? Desde nuestro presente, el disparador "pensar el hacer", nos sitúa en una doble encrucijada: por un lado enfrentarnos a una creciente incapacidad en los jóvenes para la puesta en palabras, empobrecimiento del lenguaje que se torna formal y desafectivizado, y una modalidad operatoria con déficit en los niveles imaginario y simbólico, un modo deslibidinizado del pensar, ligado a un accionar concreto y pragmático, carente de implicación personal; y por otro lado, cómo proveer los significantes que puedan agujerear el puro discurrir que no hace marca ni anclaje, para reconstruir el quiebre de la cadena metafórica, desde su operatoria sustitutiva y portadora de símbolos. Esto último requiere de una reflexión y puesta en acto de nuestra propia subjetividad, capaz de captar los códigos de los jóvenes y hacer lectura de sus mensajes, para poder interrogar en sus discursos, quién es el sujeto del enunciado y quién el sujeto de la enunciación. Vía de acceso a la implicación subjetiva.

Pensar el hacer, en este caso no puede ser unidireccional, requiere por lo menos de dos sujetos en vínculo dialéctico.

En la práctica docente, son constantes los trabajos que presentan los alumnos, y que con satisfacción muestran todo lo que bajaron de Internet, toda la información y todas las imágenes; un todo en bruto sin procesar, un puro lenguaje cristalizado, favorecido por los medios fílmicos, fotográficos y electrónicos, que refuerzan la captura imaginaria, narcisista, a través de una discursividad plena, donde solo aparece el sujeto del enunciado sin posibilidad de emergencia de un sujeto de la enunciación. Carencia de un posicionamiento que de cuenta de una posición subjetiva; la predominancia de un deslizamiento mínimo de significantes carentes de significación propia; retirada de la capacidad metafórica, la asociación, la representación. Sintagmas cristalizados, que en su adherencia formal, convencional, reproducen, repiten como único movimiento; repetición que es compulsiva, y adherente a un goce pulsional, que señala una muerte, la del deseo. Inercia, inmovilidad, deseo de no deseo.

Sería pertinente partir de la dificultad de poner en marcha los mecanismos imaginario y simbólico, por parte del sujeto actual, que se lo observa reforzando su registro de lo real, para 
poder ubicar mejor este déficit. Si lo real, recordémoslo, es opaco, informe e ininteligible, su acceso es a través de una construcción; la construcción de la realidad se produce dándole forma a lo real; informar es dar forma a lo real. Para que esto sea posible y la realidad emerja y se asiente son necesarios los códigos como instrumentos, herramientas que darán forma. La capacidad de significación, de traducción o interpretación de signos, dependerá del lenguaje, como productor de la realidad, ordenador y modificador, capaz de hacer soportable lo real desnudo.

El poder nombrar, nominar lo objetos, no solo estructura la percepción sino que hace posible que esos objetos existan, tengan consistencia. Lacan diría "Si el sujeto humano no denomina... en primer lugar las especies principales, si los sujetos no se ponen de acuerdo sobre este reconocimiento, no hay mundo alguno, ni siquiera perceptivo, que pueda sostenerse más de un instante".(Gonzalez Requena, J., 1989: 51) Cómo acceder entonces al signo y su capacidad semiótica que escape a su adherencia actual a lo real, sino es a través de la palabra, el significante ordenador y llave de la cultura. El lenguaje verbal es lo que institucionaliza y consolida los significados de una cultura; también los puede cristalizar desde sus discursos abusivos, intrusivos, autoritarios, si no se cuestionan y dialectizan los diversos mensajes que hoy los distintos medios culturales parecen querer imponer; en su vertiente perversa de pretender mostrarlo todo, decirlo todo, como si se pudiera mostrar lo real de lo real, con el carácter de obscenidad que hoy revelan las imágenes mediáticas.

Poner en práctica el lenguaje, darle su valor de ordenador, es poder reconocer el material con el que trabaja; el lenguaje verbal es aquel que no solo se describe a sí mismo sino también a otros como el icónico.

Para entender cómo son los materiales a los que acceden nuestros alumnos y cómo trabajarlos para que logren un vínculo que haga hincapié en la producción subjetiva, sería conveniente recordar la clasificación que hace Gonzalez Requena de las imágenes, que las divide en especulares, delirantes e icónicas.

Brevemente las imágenes especulares son las retinianas, poseyendo estas una cualidad de espejos; no constituyen signos, ya que son huellas visuales de lo que tienen allí delante. No son representativas, porque no representan algo ausente, son presentativas de ese real. Las imágenes delirantes son las que mienten, pues remiten a lo que ahí no está presente; tampoco son signos (aunque signo nombra a algo ausente), porque al mentir tan bien generan la certeza de la presencia de lo ausente. Son presentativas como las especulares, pero no ya de lo real sino de lo imaginario, o lo fantasmático.

Y las imágenes icónicas que son las únicas que pueden considerarse como signos, nombran algo ausente, no presentan sino representan la realidad, tienen carácter semiótico.

Si bien las imágenes electrónicas, fotográficas y televisivas tienen un estatuto de especulares, la huella, el espejo o reflejo de lo real, y pueden también invitar a cierta lectura semiótica o descodificación, poseen una capacidad de seducción que es lo que requeriría mayor atención. Por qué seduccción, porque lo que allí se presenta escapa al signo y a lo real, entramándose con un orden como el imaginario, el del fantasma singular. Algo se reconoce inconcientemente y es a alguna imagen identificatoria, como Lacan nombraría captura, o identificación especular o imaginaria. Lo que seduce es algo que se reconoce (no que se lee) en una fotografía, espejo u otro medio, eso que el otro como un espejo, puede reconocer en uno cuando mira con deseo. Es una imagen identificatoria, alojada en el inconciente, donde uno se quedó atado y sobre ella se construyó el yo (fase del espejo, en Lacan). Lo que allí se produce es un delirio, una imagen delirante que nada tiene que ver con lo significativo (semiótico), ni con lo insignificante (real), sino lo identificatorio; un enamoramiento de un fantasma. La seducción narcisística, imaginaria, escapa a toda posibilidad significante, al margen de códigos y de diferencias; se pega a lo mortífero, porque lo uno se fusiona, se incorpora, se devora. En las imágenes mediáticas es conveniente reconocer tanto el espejo identificatorio, tendiente a lo absoluto, al yo, a la imago narcisista; como el espejo real, independiente de toda mirada y deseo, independiente de alguien que pueda mirarlo; excesivo, capta todo, obliga a mirar todo, y esto amenaza y desordena, despoja y es inhumano.

Es en nuestro tiempo donde hay que poner el énfasis en el desorden que produce la emergencia de lo real, que ocasiona lo caótico, lo imprevisible, conoce solo la ley de lo singular, desconoce el sentido. Se desmoronan los discursos míticos, filosóficos, utópicos, que le daban una cohesión a la realidad, más allá de regiones dominadas por saberes especializados, como técnico operativos. (Gonzalez Requena, J.:1989) 
A pesar de poseer más códigos, más saberes especializados, más aparatos discursivizadores y un aparato semiótico más flexible para leer la realidad, todo indica que la crisis de nuestro tiempo se asienta en una pérdida de la dimensión simbólica capaz de cohesionar o relacionar mejor el conjunto.

Nuestra tarea tendrá que ver con cómo hacer frente a esta grieta por donde se ha filtrado lo real y que amenaza el orden de la realidad, el vacío de los diversos discursos culturales y su pérdida simbólica; que equivale tanto a pérdida de legalidad como a pérdida de prohibición, del orden necesario que instituye el estar atravesados por el lenguaje.

Al deseo de saber que reclama por una realidad inteligible, se lo permuta por un deseo diferente, el deseo de ver, que es atractivo y espectacular, satisfaciendo solo un aspecto subjetivo, el visual. La realidad entonces cobra peso desde su real de espectacularidad, alejándose de lo verosímil.

\section{Cambio de paradigma}

Ante este estado de las cosas sería deshonesto pensar que nada se puede hacer frente a tal apocalipsis cultural. Toda cultura siempre ha tenido mecanismos de defensa y de enfrentamiento de sus malestares. La obligación ético-moral de la educación será no sólo reconocer sus síntomas sino cómo preparar los caminos y las alternativas para levantar las barreras de los mismos.

El desafío, decíamos en páginas anteriores, tendrá que ver con cómo hacer de soporte para la posibilidad de la constitución subjetiva que se ve amenazada en los jóvenes.

No solo la escucha sino la acción sobre esta insuficiencia sería la clave. Acción que deberá replantear los paradigmas educativos hasta ahora vigentes.

Sin caer en las mismas soberbias de los discursos actuales, se podrían tomar como disparadores las ideas provenientes de campos como la estética, el arte. Fue primero Picasso quien revierte algunos conceptos que se manejaban en la pintura: "Yo no busco, encuentro". Luego Lacan hace suya la frase del artista para referirse al movimiento particular del inconciente.

El sujeto descentrado, de las certezas, de la completud, y de las garantías de buscar lo perdido, irá, en cambio, encontrando en su camino aquellos significantes que lo representen para otro significante. En cada apertura y cierre del inconciente se producirá un hallazgo, alguna posibilidad de saber; movimiento que reedita cada vez la puesta en marcha del deseo. Y esta es la dimensión subjetiva, la marca del deseo que conduce al encuentro de los significantes que lo representen y lo impliquen, en tanto es sujeto representado y representante.

La apertura a un nuevo paradigma: "No busco, encuentro", nos permitirá encarar un nuevo hacer con nuestra práctica educativa.

Acompañar, sostener, brindar los significantes que ayuden a construir su posición subjetiva, desde las lecturas múltiples que requiere la imagen, la interrogación de los textos, hacer letra de su decir, propiciar la escritura. Para que el proceso que se inicie tenga el circuito mismo de su acontecer psíquico inconciente: instante de ver, momento de comprender y tiempo de concluir. Quedarse en el instante de ver sería reforzar la amenaza de lo especular, que no hace más que encapsular en el yo al deseo, capturado por lo imaginario.

El momento de comprender implicaría toda una batería significante, que necesita colocar la pregunta, la interrogación en el centro.

Ayudarlos a interrogarse, poner en cuestión, buscar las preguntas, favorecer lo crítico. Tiempo de concluir, íntimo, síntesis productiva, que necesita de un acto, la concreción de un hacer traducido en palabras.

La escritura sería ese encuentro con uno mismo, la posibilidad de traducción, corrección del malentendido, hacer letra de lo que se dice; decir estaría en el orden del significante y leer o hacer letra, escritura, estaría en el orden del significado, del sentido. $Y$ de esto se trata, de recobrar el sentido. Un trabajo que invierta la ecuación vigente: discursos fragmentados, carentes de densidad semántica y cohesión discursiva, vacíos de contenido; por discursos narrativos que construyan un tiempo sincrónico constante y reconocible, dotado de sentido, restituyendo la cadena simbólica.

\section{La síntesis creativa}

Respecto de la escritura se podrían puntualizar otros aspectos, tomando como ejemplo, algunas ideas de Roland Barthes, quien distingue los lenguajes encráticos de los acráticos, como guerra de lenguajes.

Los lenguajes encráticos se desarrollan bajo la sombra del poder, através de sus distintos aparatos estatales, institucionales, ideológicos. Son vagos, difusos, aparentemente naturales pero difícilmente perceptibles. Son los de la cultura de masas, y en cierto sentido el de la opinión común, el de la conversación. 
Los acráticos se elaboran, se arman fuera del poder, o contra él. Son clandestinos, difícilmente reconocibles y, a la vez triunfantes, imposible de escapar a ellos. Son lejanos, tajantes, se separan de la doxa (opinión), son paradójicos, y la fuerza de ruptura que poseen proviene de lo sistemático, constituídos por pensamientos y no ideologías. Los ejemplos de estos últimos son: el discurso marxista, el psicoanalítico, y Barthes se permite agregar el estructuralista. También dentro de estos ubica divisiones, como son los discursos críticos, que él llamaría ficciones (y que ve en los intelectuales).

Estos lenguajes entran en combate, una verdadera guerra; las armas de combate de estos son de tres tipos:

- Una representación (un show), una puesta en escena de argumentos, agresiones, fórmulas.

- Figuras de sistema (figuras de retórica), formas parciales del discurso para dar una consistencia absoluta.

- La frase como estructura sintáctica cerrada, que es un arma, un operador de intimidación, toda frase acabada tiene algo de imperativo. Hay dominio de la frase cercano al poder; ser fuerte ante estas circunstancias sería acabar con las frases. La reflexión de Barthes nos puede servir de apoyo al trabajo con los jóvenes, y marca el contexto antes descrito de la actual discursividad posmoderna.

Por compromiso con nuestra época es imposible huir, sino comprometernos a participar dentro de ella. Tampoco se puede renunciar al placer, por utópico que parezca, a un lenguaje descolocado y desalienado del presente. Propone una filosofía plural de los lenguajes, desde el compromiso y del placer.

Dice del Texto, que no es la obra, y que se lee poco, es producto de la escritura, cuya producción es libre y no respeta la totalidad del lenguaje, la ley.

Siendo la escritura lo único que puede asumir el carácter de ficcional, y de mezclar las hablas. (Barthes, R.: 1973)

Es ella la que "puede permitirse burlar las reglas de la retórica, las leyes del género, todas las arrogancias de los sistemas: la escritura es atópica; respecto de la guerra de los lenguajes, a la que no suprime, sino que desplaza, anticipa un estado de prácticas de lectura y escritura en las que es el deseo, y no el dominio, lo que está circulando". (Barthes, 1973:139)

No hay creación si no hay interrogación, e interrogarse es abrir el camino del deseo, único capaz de emprender el movimiento por los senderos de la representación.
Pensar la representación dentro de un contexto donde el sujeto parece estar perdido, ocluído, detrás de las palabras y las cosas, será pensar en desconstruir los códigos actuales por su intento de erigirse como los únicos absolutos modos verdaderos de representación.

Y es dentro del tesoro de la lengua por donde se pueden interrogar los lenguajes de las imágenes y los lenguajes de las palabras.

Si es la escritura un intento de reconstruir el espacio simbólico, subjetivo; también "la descomposición de un universo continuo de elementos ópticos, diferenciados e identificables es una operación de abstracción conceptual y cultural." (Schnaith, N., 1987: 26,27)

El espacio visualmente representado, es un espacio a simbolizar, metaforizar, conceptualizar.

Por eso pensar la imagen es un trabajo también de lectura, de escritura, donde intervienen los códigos del saber, de la percepción y de la representación, relacionados dialécticamente. "Cuestionar la representación y sus relaciones con lo real y verdadero somos nosotros mismos los cuestionados como así también la realidad con la que creemos tratar". (Schnaith, N., 1987: 29) Es nuestro trabajo promover una lectura crítica de los discursos que se ven, se conocen o se representan, tanto sea el de las cosas, las imágenes o las palabras; para preguntarnos por lo real que supone también lo irreal, lo imaginario. Lo imaginario en su vertiente de deseo, productor de fantasmas; como la imaginación en tanto independencia en la imagen de lo percibido, y por el lenguaje que en sus signos la produce.

En toda imagen sea percibida o representada, está el sujeto y sus condicionamientos, culturales, personales, sociales, inconcientes, lingüísticos, que afectan tanto la verdad de la representación del objeto, como la del sujeto. Ver y representar dentro de una cultura visual, implican un movimiento subjetivo que va desde el reconocimiento de los códigos que constituyen una época, como el cuestionamiento de los mismos para una transformación de la realidad tanto del objeto como del sujeto; permitiendo una apertura constante a los múltiples contextos de referencia (subjetivos, sociales, culturales e históricos), que enfrenten una realidad gobernada por el prejuicio, los estereotipos y la costumbre.

Para ir intentando un cierre a partir de lo expuesto, se podría colocar en el centro de nuestra cuestión a una educación que proclama por una metodología más creativa en la enseñanza de carreras con una fuerte base 
comunicativa; debate que será necesario retomar. Dentro de la multiplicidad de los discursos visuales, en una época donde la reproducción técnica (de los medios masivos de comunicación) promueve la cultura del cambio (nada permanece, todo cambia), se ensancha la brecha entre lo singular y la repetición, siendo la multiplicidad la cara del retorno de lo mismo. Por esto resulta imprescindible una lectura creativa de los distintos discursos actuales, para ubicar allí al sujeto observador y al objeto observado, en sus dimensiones semánticas y psicosociológicas; ya que en todo texto visual se articulan el ver y lo visto en torno a una estructura de " hacer -ver (mostrar, exhibir) como actividad del enunciador y un ver-hacer (mirar) como actividad propia del enunciatario."(Zunzunegui, S., 1992: 83)

Esto presupone la puesta en acto de una comunicación, una conversación, que implica en el espectador un intercambio simbólico, una lectura del texto (visual, escrito,etc.) en tanto trama de múltiples significantes; logrando esta productividad el pasaje de un instrumento de cambio a un valor de uso, en una ganancia de placer hacia el texto.

Desde esta perspectiva se podría abrir un proceso continuo de interrogación a los binomios creación-recreación, presentaciónrepresentación, reproducción-producción, para correr la lógica de la simulación (presente en la imagen contemporánea o de los media) a una lógica del sentido, donde las distinciones entre verdad y mentira, realidad e imaginario, falsedad y secreto, demandan un cuestionamiento constante.

Quizás, si la enseñanza dentro de carreras de base proyectual y comunicativa tomaran algunos principios filosóficos del arte, estaríamos propiciando una educación crítica, capaz de promover la autonomía desde una responsabilidad interpretativa, que reniega de los dogmas para consolidarse como intérprete de un estilo propio. Sólo como intérprete la verdad se deja abrir en toda su complejidad. "Para el pintor, lo incitante nunca es una forma servida sino el hecho de poder dar forma. El crear antes que lo creado y lo creado apenas como lo que remite al flujo infinito del acto creador." (Kovadloff, S., 1993: 135) El sujeto actual, heterónimo, cuya identidad cartesiana se vio derrumbada, vive en un tiempo donde la certeza de que existe no proviene de su pensar, sino de la constante tensión entre la realidad y el deseo de aprehensión de ella.

\section{Bibliografía}

Barthes, Roland

(1973), El susurro del lenguaje. Más allá de la palabra y la escritura, Barcelona, Paidós Comunicación.

Diaz, Esther

(1988), Posmodernidad, Madrid, Biblos.

González Requena, Jesús

(1989), El espectáculo informativo o la amenaza de lo real, Madrid, Ediciones Akal.

Kovadloff, Santiago

(1973), El silencio primordial, Bs. As., Emecé Editores.

Rojas, María Cristina y Sternbach, Susana

(1994), Entre dos siglos, Una lectura psicoanalítica de la posmodernidad, Bs. As., Lugar Editorial.

\section{Schnaith, Nelly}

(1987), Los códigos de la percepción del saber y de la representación en una cultura visual, Ponencia en el Primer Congreso de Diseño Gráfico y Comunicación Visual, en Revista Tipográfica $N^{\circ} 4$.

\section{Zunzunegui, Santos}

(1992), Pensar la imagen, Madrid, Edit. Cátedra/Univ. del país Vasco. 